\title{
Haceres de saberes disruptivos: las comunalidades creativas
}

\section{Making Disruptive Knowledge: Creative Communalities}

\section{Resumen}

En estas páginas pongo a consideración de les lectores una búsqueda de maneras otras de producción de conocimiento que buscan transitar una forma de haceres-pensares producidos comunalmente. En la convicción de que el saber-en-lugar potencia la creatividad y que el sistema educativo en todos sus niveles es uno de los factores que inciden decididamente en la condición colonial de nuestras sociedades, retomo acá experiencias extendidas en el tiempo que pretenden romper con ese patrón.

Palabras clave: Colonialidad del saber; comunalidades creativas; disrupción pedagógica.

\begin{abstract}
Over these pages I share with the readers a search of other ways of knowledge production that look for ways of making-thinking communally. With absolute certainty that knowing-locally fosters creativity and that formal education is one of the factors that definitely reinforces coloniality in our societies, I here narrate significant experiences that aim to break free from such colonial patterns.
\end{abstract}

Keywords: Coloniality of knowledge, creative communities, pedagogic disruption.

\footnotetext{
${ }^{1}$ Profesora emérita de la Universidad Nacional de Salta (UNSa). Correo: zulmapalermo@gmail.com
} 


\section{Introducción}

Mientras la violencia de los opresores hace de los oprimidos hombres a quienes se les prohíbe ser, la respuesta de éstos a la violencia de aquellos se encuentra infundida del anhelo de búsqueda del derecho de ser.

Paulo Freire

(Pedagogía del Oprimido)

En tu mezcla milagrosa

de sabihondos y suicidas, yo aprendí filosofía, dados... timba...

y la poesía cruel

de no pensar más en mí.

(“Cafetín de Buenos Aires")

Caminar en pos del des-prendimiento del patrón colonial de poder ${ }^{2}$ en el espacio del hacer pedagógico nos ${ }^{3}$ condujo a concretar experiencias alternativas a las que constituyen los cánones instituidos. Para ello venimos proponiendo espacios otros dentro de la academia, espacios en los que es posible concretar variadas formas de haceres-saberes persiguiendo la "búsqueda del derecho a ser" que reclama P. Freire. Tratamos, en todos los casos, de proponer formas alternativas de generación de conocimiento des-prendiéndonos de lo que la ratio occidental prescribe, para dar lugar a maneras otras de conocer y descubrir, de hacer y pensar como opciones a lo existente.

Desde el momento en que nuestro lugar -y apelamos acá al sentido que Arturo Escobar da a la noción ${ }^{4}$ - se ha construido durante muchas décadas en el aula, nuestra práctica, nuestro hacer, se encuentra acotado a ella en tanto experiencia generadora de saberes, participando con distintos sujetos portadores de memorias diversas, con experiencias vitales y dentro de sistemas de producción heterogéneos. Ese es el espacio en el que se concretó y concreta nuestro "trabajo de campo", a diferencia de antropólogos, etnólogos, y sociólogos. Queremos decir: nuestra práctica -que intenta perseguir metas decoloniales $y$, en consecuencia, políticas y éticas- no se realiza con comunidades indígenas

\footnotetext{
${ }^{2}$ Sobre esta línea de pensamiento circula abundante bibliografía. Ver esp. Aníbal Quijano (2014).

${ }^{3}$ El plural en este caso no apela a la modestia ni a la despersonalización del discurso propio, sino que lo que se acá narramos es el resultado de una práctica comunal, hecha y dicha por todxs los que participamos en ella.

4 Esta concepción de "lugar" es política y epistemológica, surgida de un discurso anti esencialista de lo diferente. (Escobar, 2000).
} 
ni de afrodescendientes sino en el aula, con grupos estudiantiles de diversos niveles de escolaridad y pertenencia social, caracterizados -mayoritariamente como decía- por la heterogeneidad de sus procedencias y competencias.

En una temprana publicación dábamos cuenta de las primeras incursiones en esta dirección, dejando abierta la expectativa a su continuidad y diseminación. Escribíamos entonces:

Con estas acciones concretadas en distintos escenarios -escasas y muy parciales aproximaciones a una transformación profunda del sistema educativo- ensayamos la reconstrucción de tramas comunitarias del saber y de las subjetividades, desintegradas por la colonialidad estructural [...] Creemos que es sólo restituyendo la fuerza del tejido social [...] que será factible avanzar en la generación de sociedades solidarias y verdaderamente participativas. (Palermo, Z., 2014a: 134)

Es desde ese lugar de deseo y de expectativa que venimos abriendo los espacios sobre los que acá exponemos para la acción productiva de lo que, con Adolfo-Albán Achinte, venimos llamando comunalidades creativas. Entendemos por tales aquellas formas de acción en común generadas por la gestión de un grupo mancomunado geocorpolítcamente en un lapso de tiempo limitado, para dar lugar a una producción socializada de conocimiento, ya sea se centre en lo epistémico, económico, pedagógico o artístico, desbordando esos ejes para permear todas las otras formas de producción social. (Palermo, Z., 2016)

Si entendemos que estas prácticas tienen en sí mismas un valor pedagógico orientado a darnos re-exitencia ${ }^{5}$ como sociedades aún hoy colonizadas, todas aquellas tendientes a alcanzar esa finalidad, según nuestra experiencia, revisten ese valor. Por eso es que el abanico de acciones que venimos gestando -todas ellas en espacios institucionales -se concretan en diversos modos expresivo-especulativos partiendo de haceres particulares, para pensar ámbitos posibles de conocimiento transformador. Sin embargo, es necesario señalar que lo que acá ofrecemos no quiere ser un recetario metodológico, sino que pone en circulación relatos de experiencias que se concretaron como escenarios de creatividad en interacción. Para ello fuimos interviniendo en el campo institucional intentando generar "nuevos territorios de existencia y nuevas formas de ser en comunidad" como invita Arturo Escobar. (2016: 226)

Poco a poco fuimos encontrando resquicios en distintos niveles de la educación formal, en la convicción de que es allí donde recae el peso de la colonialidad con mayor eficacia en la formación de las subjetividades, para imaginar y proponer alternativas. Estos haceres pensantes salidos de la experiencia que se amasa desde las opresiones y los fracasos,

\footnotetext{
${ }^{5}$ Para Albán-Achinte la re-existencia consiste en "los dispositivos que las comunidades crean y desarrollan para inventarse cotidianamente la vida y poder de esta manera confrontar la realidad establecida por el proyecto hegemónico que desde la colonia hasta nuestros días ha inferiorizado, silenciado y visibilizado negativamente las comunidades afrodescendientes" (2014: pag. 60, infra).
} 
sintetizan muchas de las cuestiones que se han ido suscitando: la necesidad de responder desde la propia cultura desprendiéndonos de los moldes impuestos para empoderar el propio hacer, para redescubrirnos en estas prácticas nacidas tanto de la información que proveen los conocimientos previos como de las vivencias e imágenes de nuestra memoria, apropiándonos a la vez de algunas "nuevas tecnologías".

Sin diseño previo, con cada experiencia, con cada grupo participante se fueron inventando nuevos rituales, haciendo nuestras muchas veces las formas de relacionamiento propias de las comunidades afrodescendientes y originarias que dieron sustento a las diversas comunalidades cuyos haceres-pensares relatamos acá en breve síntesis ${ }^{6}$.

\section{Pensando en re-unión}

Nuestra memoria registra el comienzo de estas prácticas apenas iniciado este siglo, a partir de seminarios de grado y de posgrado en las Universidades de Salta y de Jujuy, en principio centrados disciplinarmente en los estudios literarios para irse expandiendo paulatinamente a las exploraciones en el campo mayor de las políticas culturales en espacios locales, desde una dimensión más transdisciplinar orientada por la crítica a la modernidad/colonialidad. 7

Uno de los primeros encuentros que llevaron a la sistematización de estas formas de pensar desde el hacer encontró su espacio en un Coloquio propiciado por el CIETP de la Universidad de Rosario en el año 2011, para discutir acerca de "los términos clave de la teoría poscolonial latinoamericana" y que denominamos Conocimientos de otro modo: la opción decolonial y la academia argentina.8 La propuesta de realización de este encuentro surgió con la finalidad de generar un espacio alteracadémico en el que se pudiera dar comienzo a un des-prendimiento del modelo de producción de conocimiento por la academia occidental y decimonónica, tal como ésta en la que hemos sido formados, y a la que damos continuidad con nuestras prácticas epistémicas y pedagógicas. Con ello, desplazar el principio de autoridad de una sola forma válida de conocer, para instaurar una voz común en la que todos podamos sentirnos partícipes igualitarios sin construir un nuevo lugar de poder, en el convencimiento de que no es suficiente transformar lo que se dice sino también el cómo se hace si queremos construir "un mundo en el que quepan muchos mundos".

\footnotetext{
${ }^{6}$ Las crónicas completas de estas acciones se encuentran reunidas en Palermo,Z. 2014 a .

${ }^{7}$ Nuestros procedimientos: a partir de convocatorias institucionales acreditadas se propone a los participantes generar un espacio dialógico presencial acompañado de intervenciones a distancia en el tiempo que media entre cada encuentro para retroalimentarlos. Una vez concluido el tiempo presencial, nos proponemos dar continuidad a los intercambios virtuales por el tiempo necesario. Estos procedimientos que van siendo permanentemente enriquecidos por quienes siguen reunidos en virtualidad, van dando forma a una crónica en la que se incorpora más información bibliográfica.

${ }^{8}$ Publicado en versión digital por Catelli y Lucero en 2013.
} 
Surgió así la pregunta sobre las reales posibilidades para instaurar una voz desde un lugar "otro", ya que se estaban produciendo epistemes "otras" localizadas en los movimientos sociales, en el pensamiento de muchos colectivos (en particular indígenas, afrocaribeños y de género) que empezaban a tener eco en los espacios académicos. Los extendidos intercambios permitieron recorrer los espacios de encuentro y desencuentro entre las distintas maneras de comprender el presente en nuestras localizaciones, asumiendo una voz plural en ningún momento unívoca. El trabajo interdisciplinario e interregional acá concretado llevó a plantear la necesidad de inaugurar una lingua franca que hiciera posible el diálogo, pero que evitara reproducir las relaciones históricas de poder por las que los paradigmas epistémicos europeos y norteamericanos se vuelven dominantes mediante la apropiación del pensamiento emergente en América Latina.

A partir de esta acción académica con efectos especulativos, se fueron abriendo otros espacios pluriversos en los que la interacción se concretó desde búsquedas con otro tipo de participantes. Así el colectivo autodenominado Nuevas juventudes, subjetividades otras en cuyo transcurso los jóvenes que hicieron escuchar su palabra (estudiantes universitarios de grado) se dijeron a sí mismos como fuerzas geo y corpopolíticas capaces de dar forma a nuevas subjetividades desprendidas de las del poder y afirmados en las carencias con las que la sociedad los constriñe. Se sentían así incorporados a una forma de resistencia que no se reduce a planteos puramente discursivos sino que forman parte de un prolongado movimiento extendido desde la Reforma argentina de 1918, a los levantamientos pachucos en Los Ángeles de 1943, la protesta estudiantil en la Plaza de las Tres Culturas en México de 1968, la Revolución de los Muchachos Sandinistas de 1974, la Rebelión Zapatista de Chiapas en 1994, los movimientos antiglobalización mundiales persistentes hasta la aparición de la pandemia que hoy transitamos9.

Sumado a ello escuchamos algunas Voces de niños entre el desamparo y la inocencia perdida que hablaron desde las periferias de nuestras ciudades andinas visibilizando la conciencia de su no-ser-para-los-otros, descubriendo los dispositivos por los que están condenados a vivir-morir en el más doloroso abandono. A la vez, en un Darse cuenta y dar cuenta10 de las formas de hacer pedagogía se levantó una fundada crítica al mandato del paradigma eurocentrado inscripto en el Encuentro de Cátedras de Investigación Educativa y de Equipos de Investigación de la Provincia de Salta en el que intervinieron docentes de todos sus Departamentos, desde los vallistas a los puneños, atravesando el chaqueño.

Estos primeros andares dieron sustento a otras instancias de participación posteriores las que, extendidas en el tiempo y en distintos espacios institucionales fueron alimentando

\footnotetext{
${ }^{9}$ De marzo a setiembre de 2020 y en continuidad.

10 Relato de Siñanis, C. (2014)
} 
nuestra búsqueda, en recorridos múltiples y con efectos diversos, algunos de los cuales cronicamos acá en acotada síntesis11:

Encuentro sonoro en un andar decolonial

Fue esta una experiencia de alto grado de participación comunal convocado por FLADEM Salta12 integrando a músicos profesionales, docentes, intérpretes individuales y grupales, con formación específica y sin ella, centrada en la producción e interpretación. Este acontecimiento tuvo lugar en esta localización arraigada en la tradición de base criolla, pero buscando crear un sentido distinto al prevalente del concepto "regional", de alta impronta colonizante y fuerte penetración en el imaginario local y nacional. Se puso allí en juego un hacer-saber en el que el valor de la memoria social se instaló como eje de las expresiones, abriéndose las fronteras sonoras mucho más allá del pequeño espacio de pertenencia, a la vez que se hizo uso de las innovaciones concretadas por la incorporación de instrumentos no tradicionales y de incursionar en lo que desde hace tiempo se denomina "música de fusión".

Se fue perfilando, de este modo, la potencialidad de un hacer-pensar en común, pensamiento emergente de una forma de producción que no desecha los saberes previamente construidos, sino que los operativiza desde la puesta en acto de su productividad. Una exploración que se alimenta también en las manifestaciones del ritmo hecho danza y sonido, muestra la dilusión de los limites disciplinares entre distintas formas de expresión artística según el paradigma operante por el canon occidental, actualizando las relaciones conflictivas propias de la arraigada diferencia entre culto y popular y poniendo el acento en expresiones que insinúan formas aestéticas, Fue ésta una forma de acción que puso en juego una forma de trabajo que privilegió un hacer de abajo hacia arriba y horizontalmente, pero incorporando también, cuando se hacía necesario, elementos de arriba hacia abajo, con la actualización de saberes decoloniales ya consolidados que retroalimentaron la construcción del colectivo. En ese andar fuimos escuchando y aprendiendo, como llevados de la mano, los modos según los que cada maestrx avanza haciendo-hacer música placenteramente., como lo expresa Fabiana Barraza13:

Durante este encuentro hablé con mucho fervor de la des-canonización de la música. Muchos pueden pensar que me contradigo por mi trayecto formativo, por el instrumento que elijo para transmitir lo que siento, viviendo en una región tan rica en expresiones populares, por eso vamos a desmenuzar el concepto. Canonizar es establecer y legitimar como única una música por sobre otra, desconociendo la oralidad, la diversidad, entendiendo que si no lees música no sos músico; para colmo la música de ciertos períodos, que solo es validado como músico aquel que

\footnotetext{
${ }^{11}$ Las crónicas completas en Palermo, Z. (Coord) 2020.

12 Foro Latinoamericana de Educación Musical.

${ }^{13}$ Egresada de la Escuela de Música y docente, desarrolla un importante trabajo musical en la Provincia de Jujuy.
} 
canta afinado, desconociendo que en nuestras culturas la diversidad de expresiones vocales enriquecen la individualidad.

\section{Haceres y decires des/decoloniales. De la estética a la aestesis}

Un ámbito de acción distinto es el que abrió una nueva experiencia de mayor envergadura, tanto en el orden institucional como en el de los actores que a ella se integraron. La puesta en juego de una actividad artística que desafió en gran medida el estatuto académico a partir de la producción de un mural con participación abierta, dio lugar a un diálogo en el que se advirtió un abanico de lugares de enunciación, con prevalencia de voces atravesadas por el discurso de la modernidad y posmodernidad, en alternancia -por momentos conflictiva- con las que advertían acerca de otras miradas posibles sobre el "objeto estético". Este nucleamiento en el Colectivo Aestéticas Decoloniales14 dio prueba, una vez más, de las tensiones y dificultades que conllevan las búsquedas de desprendimiento del pensamiento de la modernidad. A partir de la creación de un mural hecho por muchas manos, se puso en juego un com-partir espontáneo propiciando un ritual comunicativo a través del trazo y el color que permitió concretar un texto único expuesto a la mirada pública. La creación del mural gestado comunalmente -y en cuyo diseño previo y posterior concreción desde un hacer en el que las individualidades se mancomunaran en pos de un fin común- no encontró igual cauce en el intercambio de reflexiones acerca del trabajo conjunto antes realizado para la generación de conocimiento alternativo.

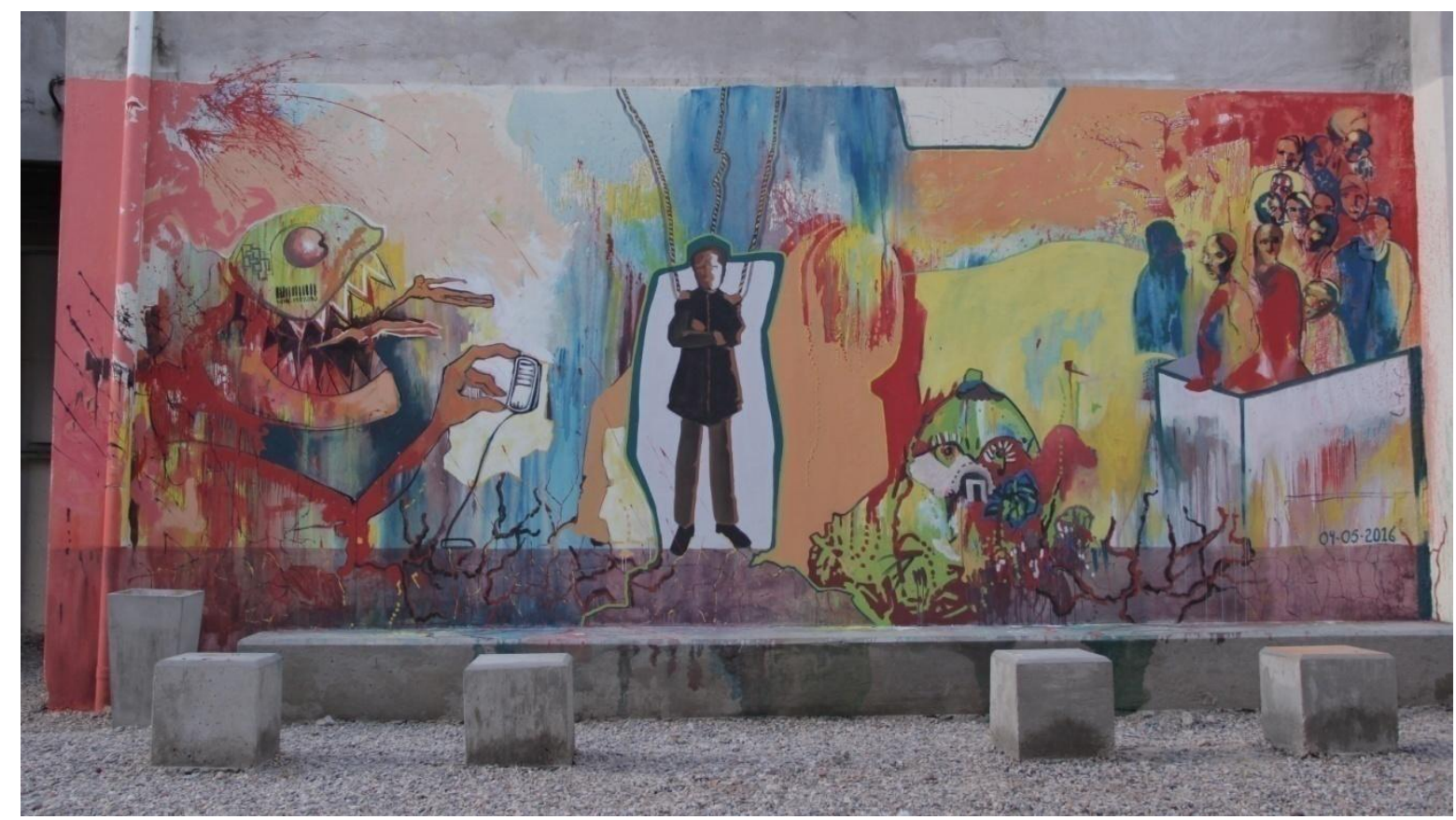

${ }^{14}$ Como parte de las Jornadas organizadas por la Maestría en Estéticas Latinoamericanas de la UNTREF (2016) 
El recorrido de esa experiencia advierte acerca de que no sólo es necesario modificar arraigadas metodologías para dar lugar a condiciones distintas de producción de saber, dejándonos atravesar por otros modos de vivir y de pensar, al decir de Enrique Dussel, transmodernas (Dussel, 2006), sino que se requiere -y más definidamente- de la convicción de su necesidad.

\section{Saberes de sabores, colores, sonoridades y decires o de la desobediencia al deber ser15}

Esta fue la disponibilidad que se encontró, en cambio, en una nueva convocatoria para generar un vínculo comunal -también en espacio educativo y con participación heterogéneacomo se lee en la crónica firmada por el autodenominado Colectivo Andino Estéticas Decoloniales16. Fue acá la puesta en acto de un evento polifónico en el que sabores, saberes y decires se entramaron para la escucha múltiple concretada en murales, canciones, comida compartida y diálogos conceptuales. Resultó así significativa la puesta en juego de la dimensión política de la mirada aestética como fuerte alternativa a la del arte académico encerrado en museos, galerías y discurso institucional. Junto a ello, la potencia de las comunalidades creativas -en este encuentro integrada por miembros de Ni Una Menos, Mapuches, Grafiteros y Raperos y también los Académico)- para caminar mancomunados hacia un posible pluriverso.

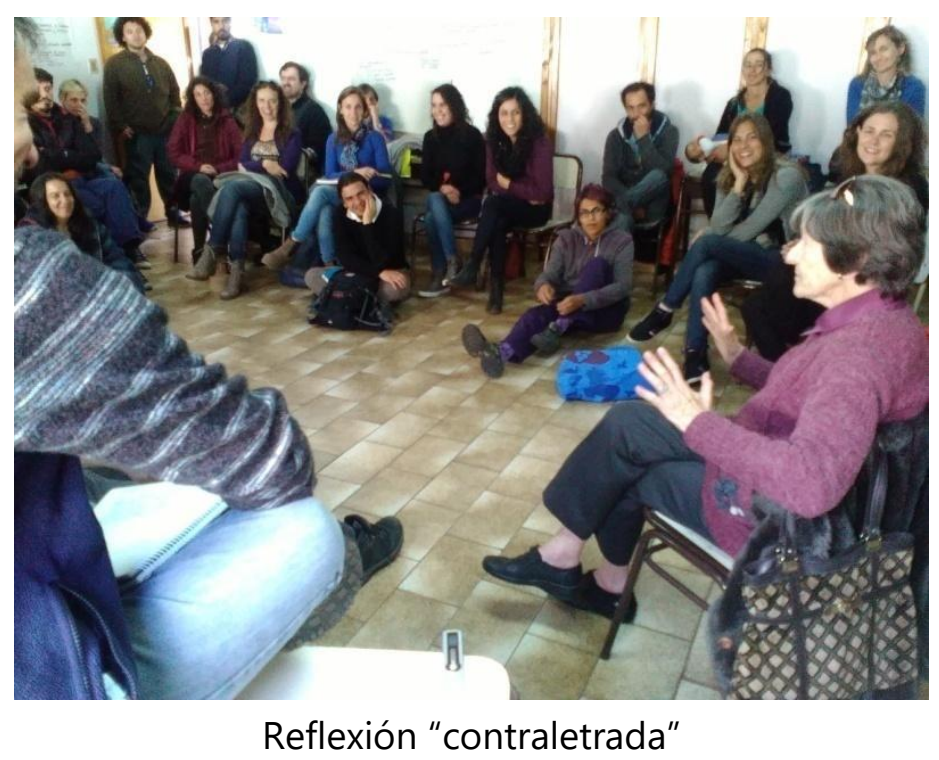

Es por esto que entre nosotros se fue conformando esta particular comunalidad creativa, cruzando cómplices miradas, disintiendo sin enojo, más bien riendo y acordando en las mutuas diferencias. De este modo se encontró una manera de restaurar nuestra humanidad

\footnotetext{
${ }^{15}$ Publicado inicialmente en Revista virtual del CEAPEDI Otros Logos, $\mathrm{N}^{\circ}$ 8, diciembre de 2020.

${ }^{16}$ Encuentro convocado por el CEAPEDI, Universidad Nacional del Comahue, 2016.
} 
borrada y travestida por el humanismo que inventó el pensamiento etnocéntico de la europeidad17. Así, comunalmente, muchos empezamos a hacer con las manos, los cuerpos, las mentes $y$, haciendo, inauguramos la posibilidad de creer de nuevo en un mundo hecho de muchos mundos; que es posible en medio de la embestida del poder re-colonizante de estos tiempos de globalización y robotización por la economía y su herramienta, por el uso exacerbado de la tecnología. Dicho de otro modo: pasar de la existencia a la re-existencia desde el re-descubrimiento de lo que somos y nunca pudimos ser. (Albán-Achinte, 2014)

\section{Pensar y decir comunalmente}

Si entendemos que estas prácticas creativas tienen en sí mismas un valor pedagógico orientado a darnos re-existencia como sociedades aún hoy colonizadas, todas aquellas otras tendientes a alcanzar esa finalidad revisten ese valor, como se lee en el relato del Colectivo Transdisciplinar18, espacio comunal pensado para reflexionar acerca de los múltiples problemas que afectan a la educación en estos tiempos de penuria y que se integró con estudiosos de varias de nuestras disciplinas. La andadura concretada a través de un largo tiempo de contacto e intercambios puso a carne viva las personales heridas coloniales -que resultaron generalmente compartidas- y la necesidad de encontrar estrategias para su restauración. El relacionamiento a través de la palabra propia, liberada de las censuras a las que nos encontramos sometidos, resultó en un momento insuficiente y reclamó las del metafórico decir de la poesía para conducir, finalmente, al impulso de hacer sentidos con el cuerpo, formas expresivas que le dieron mejor cauce al difícil proceso de desprendimiento.

\footnotetext{
${ }^{17}$ Para una crítica al humanismo y las Humanidades ver Palermo, Z. (2020b)

${ }^{18}$ En el Seminario de Posgrado convocado por el CISEN de la Universidad Nacional de Salta, 2018.
} 


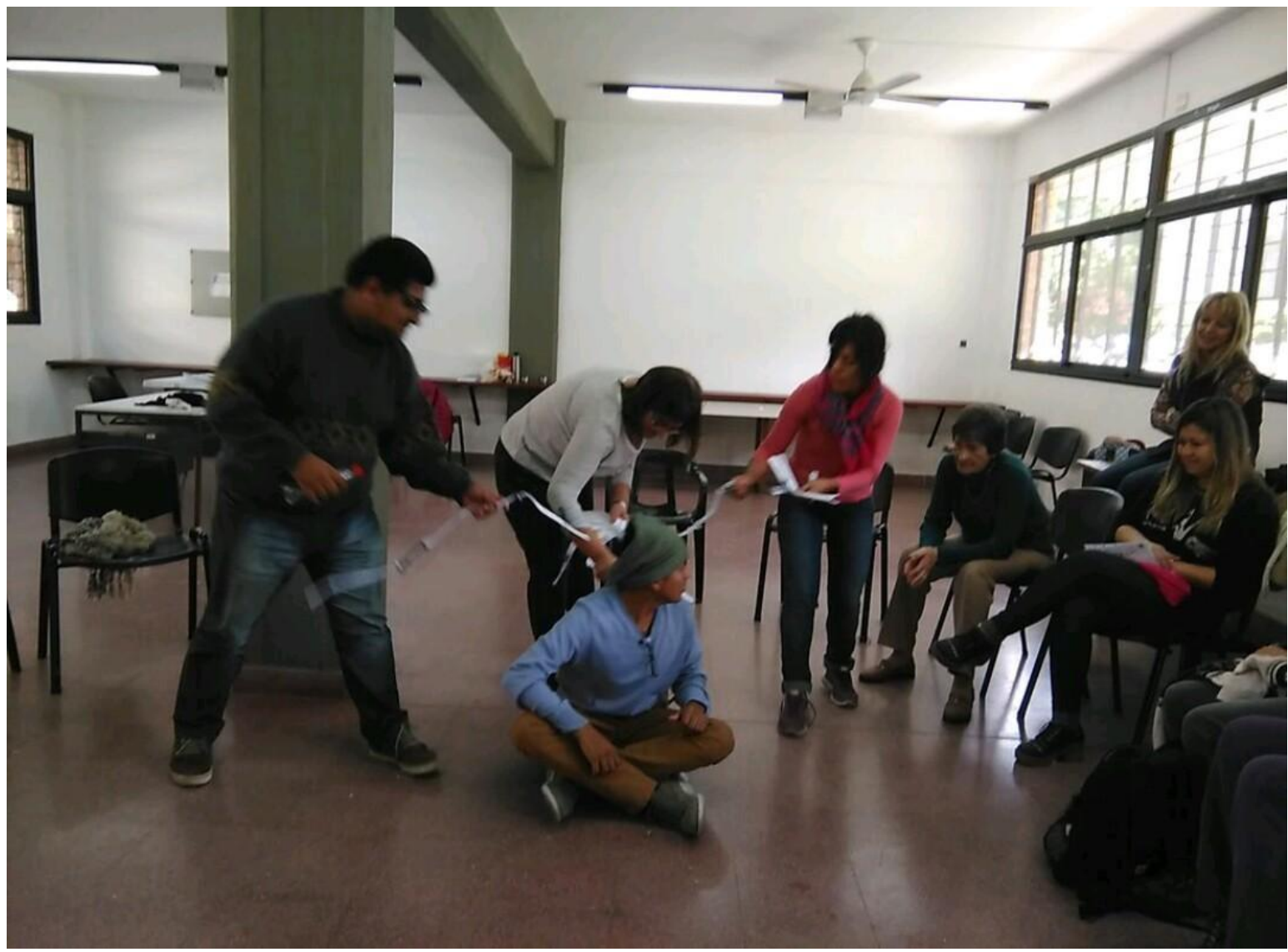

De todas estas voces aprendimos que lo que acá aconteció es una creación común porque es la primera vez entre nosotros que la comunidad incorpora sus haceres al espacio académico rompiendo los estatutos jerarquizados de producción de conocimiento. En este aquí y ahora en el que se ha puesto en acto un abanico de conceptos preexistentes que dan cuenta de la diferencia colonial que nos atraviesa para, desde allí, romper con la concepción canónica del "arte" y los estatutos con los que nos rigen. Se produjo así entre nosotros un real desprendimiento de los estereotipos formales que estructuran los espacios académicos buscando "desaprender para aprender", como lo entiende el Amawtay Wasi.

\section{Fronteras del decir: más allá de los cánones. La formación docente en Letras}

Un encuentro en el territorio de las Letras con docentes formadores en la disciplina literaria -seguramente una de las más claramente signadas por el poder de la escritura alfabética- volvió a poner en discusión, con otros actores y diferente formación específica por el Colectivo Literatura en Cuestión19- una reiterada problematización téoricopedagógica. Se buscaba acá encontrar alternativas a los mandatos inveterados previstos para la transferencia de conocimiento literario en la formación específica. Acá también la

${ }^{19}$ Encuentro convocado por la Escuela de Letras de la Facultad de Humanidades, UNSa, 2016. 
mirada crítica acerca de las prácticas instituidas, reclamó la escucha de las propias del lugar de producción al desbrozar las particularidades sociodiscursivas del discurso del carnaval como expresión espectacularizada del dinamismo y fluencia de un espacio fronterizo. Por eso la escucha de la voz de Ana Camblong fue acá imprescindible:

Los insensatos estudiantes de letras que venimos del borde y seguimos por el bordecito, tan sólo intentamos saber algo, en algún aspecto [...] Así cuando atravesamos nuestras letradas carreras cabalgando sobre el horror al ridículo, soportamos con disimulo el traqueteo obstinado de las imposturas, nos apropiamos de algunos autores, insistimos en castigar con el latiguillo de perfectas citas, imitamos algunas poses, repetimos algunos "lugares comunes", sabemos endilgar con esnobismo el último grito de excelencia, adoptamos piruetas irónicas y ciniconas, hasta que finalmente comprendemos que con un "caballito criollo", jamás alguien que venga del borde del campo podrá convertirse en un terrateniente literario. (Camblong, 214: 67)

El diálogo quedó así abierto a nuevas e inacabadas inquietudes si buscamos pensar donde somos: hablar y hacer desde y en la pertenencia, sin dejar de apropiarse de otras formas de habitar el mundo en una actitud transmoderna, como la piensa Enrique Dussel, a través de los emergentes de la propia cultura y de las otras que quedaron excluidas por la hegemonía universalizante.

\section{Construyendo saberes otros con voces de mujer. Un hacer contracadémico}

En esta exploración en distintos territorios con personas formadas en variadas disciplinas y de distinta procedencia, surgió también -y no podía ser de otro modo- la cuestión de género. ¿Este concepto da cuenta suficiente de la complejidad que entraña la heterogeneidad de elecciones que incluye? Esta pregunta se encuentra reiterada en los enunciados de la crónica con la que el Colectivo Voces Brujas20 narra la experiencia. Quienes nos convocamos para discutir acerca de ello, jugamos el juego que se viene reiterando en este recorrido y que -para el hábito académico- resulta no sólo fuera de lugar sino también impertinente. El diálogo orientó acá a buscar la propia voz, voz disidente, en distinta asunción de rebeldía; advertir, desde el comienzo, que buscar la propia voz es plantarse ante el poder del patriarcado que habita el lenguaje porque nos impone el uso de sus formas genéricas ( $y$ del léxico) masculino, dominador, absolutista. Lo femenino en el lenguaje se encuentra vaciado de valor propio, y más todavía en este tiempo, cuando la dicotomía masculino/femenino se va diluyendo en la convicción de que las diferencias que involucra son, también, una de las formas de control manipuladas por el poder colonial. En el diálogo,

\footnotetext{
${ }^{20}$ Concretado como Seminario de Posgrado en la Facultada de Humanidades de la Universidad Nacional de Salta.
} 
el flujo permanente entre lo dicho, lo censurado y el decir la diferencia, se fue tejiendo una trama otra de sentidos, reencontrándonos, reconociéndonos, hermanándonos. Ese fue el des-armado de ideas desperdigadas en el espacio de la escritura y que dejó testimonio de otro orden del espacio-territorio y del lenguaje en el que aquí nos expresamos:

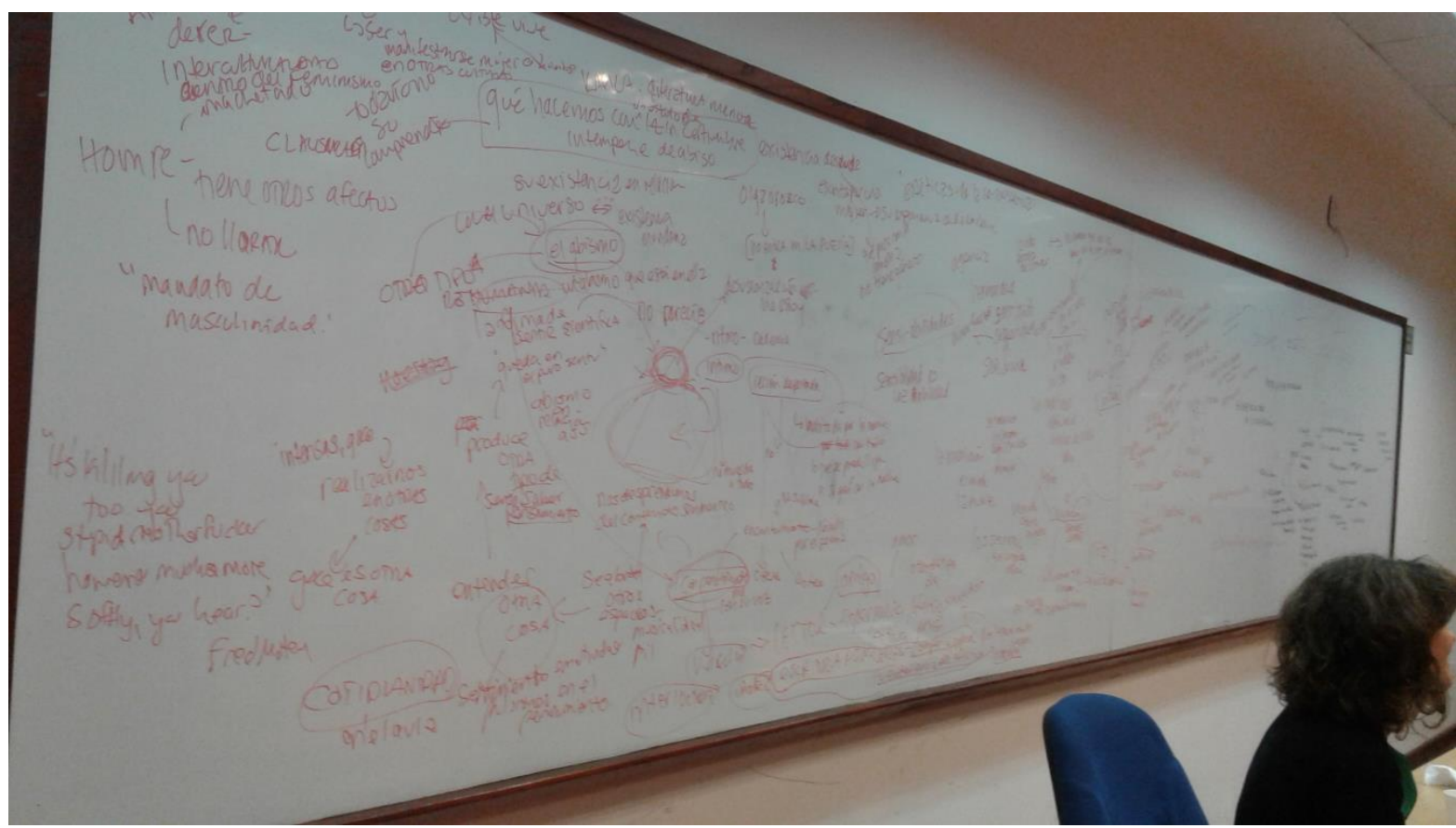

Esta fue una de las formas de apropiarnos del sentido que propone este enunciado: "¿Qué palabras son esas que todavía no poseéis? ¿Qué necesitáis decir? ¿A qué tiranías os sometéis día tras día, tratando de hacerlas vuestras, hasta que por su culpa enfermáis y morís, todavía en silencio?" (Lorde, A, 1984) que una de nosotres re-escribe con voz reencontrada:

\author{
Decir que no \\ siempre decir que no \\ anular el sí como posibilidad \\ $y$ volver a decirles que no \\ que no queremos tener bebés \\ que no nos gustan los varones \\ (o sí, pero a ellos decirles que no) \\ decir que no al vestido \\ a la misa \\ al beso del tío \\ Decirles que no,
}


anularles a ellos las perspectivas

de que nuestro existir es un sí.21

\section{Seguir pensando la vida}

La preocupación que llevó a poner en acto algunas maneras de ir generando haceres decolonizantes en la institución educativa -y muy particularmente universitaria- encontró algunos resquicios en distintos campos académicos, y creativas respuestas de quienes allí nos relacionamos reflexionando desde las competencias adquiridas en el transcurrir de la vida cotidiana.

Nos habíamos propuesto -en los comienzos- abrirnos a haceres-decires centrados en la cuestión del conocimiento para volver sobre éste con la actitud crítica que reclama el desprendimiento del patrón colonial de poder. Esa mirada crítica profundizó la percepción de que la concepción del conocimiento genuinamente moderna tiene otras formas de hacerse/mirarse/pensarse comunal y relacionalmente. Que la potencialidad para generar saberes creativos y especulativos responde al perfil de sus localizaciones con las particularidades que los hace-ser de un cierto modo. Que, entonces, no hay -no puede haber- un conocimiento universal absoluto, pues ese hacer/decir conduce a pensar en su diferencial con el pensamiento único que nos rige.

Pensar estas cuestiones hoy cuando el mundo está siendo diezmado por una peste genocida, precedida por el fuego que arrasó el pulmón del mundo, actos -como tantos otros- nacidos de la apetencia ciega y la soberbia que lleva a la explotación de nuestro hábitat en pos de "tener más", es una obligación moral. Tal proyecto fáustico nos ha colocado ante el abismo de una muerte colectiva que obliga a preguntamos: ¿será posible pensar que hay todavía tiempo para incentivar haceres-pensares-decires que conduzcan a un "mejor vivir"? Sólo aspirar a ello salva del abismo de la desesperanza. Estas páginas quieren contribuir a ello desde el lugar de quienes sólo tenemos para ofrecer un hacer pedagógico que quisiéramos fuera des/decolonizante y, por eso, revitalizador.

\section{Bibliografía referida}

Albán- Achinte, Adolfo (2014), "Estéticas de la re-existencia. Lo político del arte", en Mignolo, Walter y Gómez, Pedro Pablo, Estética y opción decolonial, Edición de la Universidad Distrital Francisco José de Caldas, pp. 281- 295.

Camblong, Ana, (2014), Habitar las fronteras..., Misiones: Editorial Universitaria.

\footnotetext{
${ }^{21}$ Andrea Mansilla.
} 
Dussel, Enrique, (2006), "Transmodernidad e interculturalidad" en Filosofía de la cultura y la liberación, México: Universidad Autónoma de México.

Escobar, Arturo, (2000), "El lugar de la naturaleza y la naturaleza del lugar" en: Lander, E. (Comp.) La colonialidad del saber: eurocentrismo y ciencias sociales. Perspectivas latinoamericanas, Buenos Aires, CLACSO, pp. 113-144.

------------, (2016), Autonomía y diseño. La realización de lo comunal, Editorial Universitaria del Cauca. Traducción de Gustavo Giecco.

Lorde, Audre (1984), La hermana, la extranjera: Artículos y conferencias, Barcelona: Lesbianas Independientes Feministas Socialistas (LIFS).

Palermo, Z. (Ed.) (2014a), Para una Pedagogía Decolonial, Buenos Aires, Ediciones del Signo, Colección El Desprendimiento.

-(Coord.) (2014b), Arte y estética en la encrucijada decolonial, Buenos Aires, Ediciones del Signo, Colección El Desprendimiento.

, (2016), "Pensar la comunicación desde la diferencia. Identidades, representaciones y visibilizaciones", en Seminario De la invisibilidad al estigma: Estudios culturales y medios de comunicación, ICSOH-CONICET, UNSA, diciembre 2016 (en prensa). (2020a), Para una pedagogía decolonial II. Haceres aestéticos, Buenos Aires Ediciones del Signo, Colección El Desprendimiento, (en prensa). (2020b), "'Habrá un después de Nuestramérica?", en Jitrik, N., González, H y Giuliano, F., El después... (Título provisorio, en prensa)

Quijano, Aníbal, (2014), "La colonialidad del poder, eurocentrismo y América Latina" en Palermo y Quintero (Comp.) Aníbal Quijano. Textos de fundación, Buenos Aires, Ediciones del Signo, Colección El Desprendimiento: 110-160

Siñanis, Cristina, (2014), "Entre el desamparo y la inocencia perdida", en Palermo, Z. (Ed.) Op. Cit $\left(2014^{a}\right)$. 